\title{
Effect of an Intensity Varied Training Program on some Antioxidants in some Water Polo Players.
}

\section{Alaa Sayed Nabih}

Lecturer at Dept. of Sports Health Sciences, Faculty of Physical Education for Boys, Al-Haram, Helwan University. Egypt.

\begin{abstract}
The objective of this research was to identify the extent of the effect of the training load of varied intensity (water polo match) on some Antioxidants represented by variables such as concentration and activity of glutathione peroxidase, glutathione reductase, malone aldehyde and amino acids in a sample of (13) water polo players of $(\ddot{X}=17.46$ years $)$. Blood samples were taken in three stages; prior to performance, directly after performance and 60 minutes after performance and relevant differences were studied. Results showed that there were significant differences between the three measurements in all the study variables in favor of the pre-measurement indicating the extent of the effect of the training load of varied intensity causing the cell damage to occur and retarding the speed recovery for athletes .
\end{abstract}

Key words: Antioxidants, Glutathione peroxidase, Glutathione reductase, Concentration and activity of malone aldehyde, Concentration of amino acids.

\section{Introduction}

$\mathrm{T}$ he field of sports training physiology is still in need of more studies and scientific researches related to reactions and responses of body organs to tackle the stresses of the training load.

The study of Mignini et al. (2008) confirmed that and they indicated that physical exercises of high intensities resulted in damaging or destruction of biological molecular composition in the cell such as lipids, proteins and amino acids. There is a correlation between increasing the oxidative stress and the level of physical performance. As long as the oxidative stress increases the level of performance decreases leading to cause fatigue, muscle damages, inflammations and excess load (8:15). Powers et al. (1999) agreed that increasing the rate of metabolism in skeletal muscles during exercise could lead to increase oxidation products. The inability to get rid of such products during exercise could result in damaging cells. Regular endurance exercise could contribute to condition the capacity of antioxidants in the skeletal muscles to protect muscle cells from bad effects of oxidation products and to minimize muscle damage (13:33).

On the other hand, Groussard et al. (2003) believed that the higher rate of oxygen consumption represented one of the essential factors to cause damages from oxidation during exercise. The results of their study carried out to identify variation occurred in blood oxidized lipids indices and Antioxidants after performing anaerobic ability exercise revealed that the performance of anaerobic ability exercise with maximum intensity could lead to oxidative stress when 
measuring MDA, SOD, GPX, GSH in rest, just after performance and within 40 minutes of the recovery period $(6: 44)$.

Goodman et al., (1997) indicated that there were several biochemical variables by which damages occurring in muscular cells could be identified and working as antioxidants such as glutathione, malone aldehyde and amino acids as glutathione was considered an oxidative enzyme mainly functioning to protect internal organs and cells from oxidation damages. For explanation, when GSH-peroxidase is activated it provides carbon to react with the oxygen atom to form $\mathrm{H}_{2} \mathrm{O}_{2}$, consequently, the activity of free radicals of oxygen atoms are minimized and GSH-Reductase is activated to reform glutathione in the form of GSH-Peroxidase once again and the same chemical reaction chain continues and thereby glutathione can minimize oxygen atoms radicals that cause fatigue and cell damages affecting the level of the athlete. There is more than $90 \%$ of the total glutathione in cells and tissues in the form of GSH standing to minimize the effect of free radicals of oxygen atoms whereas there is less than $10 \%$ of the total glutathione in the form of GSSG. The increase in the proportion of GSSG to GSH is considered as an indicator of oxidative stress. The chemical function of Glutathione Peroxidase is minimizing the proportion of lipidhydroperoxides and free hydrogen peroxide:

\section{$2 \mathrm{GSH}+\mathrm{H}_{2} \mathrm{O}_{2} \rightarrow \mathrm{GS}-\mathrm{SG}+2 \mathrm{H}_{2} \mathrm{O}$}

On the other hand, glutathione reductase transforms glutathione form GSSG to the form GSH again to be able to tackle free radicals of oxygen atoms. $1 \mathrm{M}$ of the oxidative glutathione GSSG needs $1 \mathrm{M}$ of $\mathrm{NADPH}$ to transform glutathione from the form GSSG to the form GSH again.
Malonaldehyde is not only the most important indicator of oxidative stress but it is also an indicator of lipid peroxidation, cellular malfunctions in general and damages occurring in cells and tissues illustrating that the increase in cell protein concentration in blood serum is an indicator that shows damages in muscles, however, the mechanism of occurring such damages is sufficiently not clear. Moreover, increasing amino acids in blood indicates to stress hormones (5:15-33).

Through his work as a water polo coach, the researcher has not found out a scientific study in this field aiming at knowing the effect of training load of varied intensity of water polo exercises on the level of some physiological parameters that determine damages caused due to the performance of water polo matches (intensity varied load). On the basis of what agreed by scientists that there was a clear correlation between muscular size, intensity and fatigue and metabolism, hormonal fatigue and inflammations resulted from performing that load, as the role played by antioxidants in minimizing oxidative stress is not completely clear till now and as the water polo federation has organized in some championships to hold two matches separated with 60 minutes rest and with participation of more than one players in the two matches in the same day, the researcher as a coach of the team decided to carry out measurements as follows:

1. Pre-measurement and measurement after performance directly to know fatigue parameters occurred as a result of the match (varied intensity load).

2. Measurement after $60 \mathrm{~min}$. of the end of the $1^{\text {st }}$ match before the start of the $2^{\text {nd }}$ match to know the amount of 
fatigue in the player before the start of the $2^{\text {nd }}$ match.

As a consequence, the researcher decided to conduct the current investigation to find out a parameter revealing the occurrence of muscle damages or muscle fatigue in physical activities of varied intensity during performance such as water polo. Such parameter could be used not only as an indicator of Antioxidants but also as an indicator of damages caused in muscle cells that the increase in the number of free radicals of oxygen atoms resulted from increasing such parameters leading to damages in cells and tissues.

\section{Research objective}

To identify the effect of a varied intensity training load (water polo match) on some parameters of antioxidants (glutathione, malone aldehyde and amino acids) in water polo players.

\section{Research questions}

1. Are there any significant differences in the level of concentration and activity of glutathione peroxidase and glutathione reductase in blood between the three measurements under investigation in water polo players?

2. Are there any significant differences in the level of concentration and activity of malone aldehyde in blood between the three measurements under investigation in water polo players?

3. Are there any significant differences in the level of amino acids in blood between the three measurements under investigation in water polo players?

\section{Research procedures}

\section{Research method}

The researcher used the experimental method by measuring the selected antioxidants under investigation through withdrawing blood samples (before competition, directly after competition and $60 \mathrm{~min}$. after competition).

\section{Research people and sample}

The sample was intentionally selected from individuals who have been mainly registered for the team of Al-Zohour Sporting Club. It consisted of (13) players under 18 years in water polo and their average age was (17.46) years according to the following conditions:

1. The water polo players should be volunteers, be interested in participating in the research and be prepared for the withdrawal of blood samples without the researcher's enforcement and after taking a written consent of parents (Attachment 1).

2. Making sure of the healthy status of the players before applying the research procedures.

- Application of the experiment

- The pre-measurement:

The experiment was applied at 5:00 pm on Saturday 12/1/2013 by withdrawing a venous blood sample of $(4 \mathrm{~cm})$ from each player separately by the specialized analysis doctor after carrying out clinical examination for all the research sample individuals by using the stethoscope by the doctor.

\section{- Direct post-measurement}

A blood sample was withdrawn by the specialized doctor directly after the end of performing the match consisted of 4 runs of 8 min. for each run played within the official federation matches of the republic championship in season 2013. The match was under all legal conditions followed in official matches. 
- Post-measurement (after 60min.)

A blood sample was withdrawn by the specialized doctor after $60 \mathrm{~min}$. from the end of the match by the same method and order of the players in consideration that players were in a negative rest period for one hour under the supervision of the researcher.
Statistical treatment

- Descriptive statistics.

- One way analysis of variance (ANOVA).

- Least significant difference (L.S.D).

\section{Presentation and discussion of results}

Table (1)

Arithmetic mean and standard deviation of the three measurements in the study variables $\quad(n=13)$

\begin{tabular}{|c|c|c|c|c|c|c|}
\hline \multirow{2}{*}{ Variables } & \multicolumn{2}{|c|}{ Before performance } & \multicolumn{2}{c|}{$\begin{array}{c}\text { Directly after } \\
\text { performance }\end{array}$} & \multicolumn{2}{c|}{$\begin{array}{c}\text { 60 min after } \\
\text { performance }\end{array}$} \\
\cline { 2 - 7 } & M & SD & M & SD & M & SD \\
\hline GSH-Per & 72.15 & 1.06 & 131.61 & 1.04 & 134.30 & 1.25 \\
\hline GSH-Red & 43.16 & 1.23 & 74.69 & 0.751 & 93.76 & 1.36 \\
\hline MDA & 23.84 & 0.800 & 48.15 & 0.554 & 43.46 & 0.776 \\
\hline A.As & 4.09 & 0.312 & 5.69 & 0.352 & 4.77 & 0.200 \\
\hline
\end{tabular}

Data in Table (1) illustrate the results of the experiment and the normal limits of variables were as follows:

- Glutathione peroxidase (GSH-Per) 108.8 - 41.7 U/DL.
- Glutathione reductase (GSH-Red) 80 $-40 \mathrm{U} / \mathrm{L}$

- Malone Aldehyde (MDA) 40 - 20 $\mathrm{UM} / \mathrm{L}$

- Amino acids (A.As) $5.5-3.2 \% \mathrm{mg}$

Table (2)

Analysis of variance of measurements of variables (GSH-RED, GSH-Per) in water polo players

\begin{tabular}{|c|c|c|c|c|c|c|}
\hline Variables & $\begin{array}{l}\text { Source of } \\
\text { variance }\end{array}$ & $\begin{array}{l}\text { Sum of } \\
\text { squares }\end{array}$ & D.F & $\begin{array}{l}\text { Mean of } \\
\text { squares }\end{array}$ & $\mathbf{F}$ & Significance \\
\hline \multirow{2}{*}{ GSH-Per } & Between groups & 32092.76 & 2 & 16046.38 & \multirow{2}{*}{$1268.31 *$} & \multirow{2}{*}{0.000} \\
\hline & Within groups & 45.53 & 36 & 1.26 & & \\
\hline \multirow{2}{*}{ GSH-Red } & Between groups & 16554.05 & 2 & 8277.02 & \multirow{2}{*}{$6288.39 *$} & \multirow{2}{*}{0.000} \\
\hline & Within groups & 47.38 & 36 & 1.31 & & \\
\hline
\end{tabular}

*Significance $<\mathbf{0 . 0 5}$

Data in Table (2) illustrate that there are statistically significant differences among the three measurements under investigation (pre and directly after the end of performance and
$60 \mathrm{~min}$. after performance). Significance of differences was computed through L.S.D as illustrated in Table (3). 
Table (3)

Significance of differences among the three measurements in (Red-Per)

\begin{tabular}{|c|c|c|c|c|c|}
\hline Variables & Measurements & Mean & $\begin{array}{c}\text { Pre- } \\
\text { measurement }\end{array}$ & $\begin{array}{l}\text { Directly after } \\
\text { performance }\end{array}$ & $\begin{array}{l}60 \text { min. after } \\
\text { performance }\end{array}$ \\
\hline \multirow{3}{*}{ Per } & Pre- & 72.15 & $\ldots \ldots$ & $-59.46 *$ & $-62.15^{*}$ \\
\hline & Directly after the end & 131.61 & & ........ & $-2.69 *$ \\
\hline & $60 \mathrm{~min}$ after the end & 134.30 & & & $\ldots \ldots$. \\
\hline \multirow{3}{*}{ Red } & Pre- & 43.76 & ......... & $-30.92 *$ & $-50.00 *$ \\
\hline & Directly after the end & 74.69 & & ...... & $-19.07 *$ \\
\hline & $60 \mathrm{~min}$ after the end & 93.76 & & & ........ \\
\hline
\end{tabular}

Data in Table (3) illustrate the following:

- There are statistically significant differences between the pre and directly after the end of performance measurements in favor of directly after the end of performance measurement. Also there are significant differences between the pre and $60 \mathrm{~min}$ after the end of performance measurements in favor of $60 \mathrm{~min}$ after the end of performance measurement as well as between directly after the end of performance and $60 \mathrm{~min}$ after the end of performance measurements in favor of $60 \mathrm{~min}$ after the end of performance measurement in assessing glutathione peroxidase (Red).

- Also there are statistically significant differences between the pre and directly after the end of performance measurements in favor of directly after the end of performance measurement. Also there are significant differences between the pre and 60 min after the end of performance measurements in favor of $60 \mathrm{~min}$ after the end of performance measurement in assessing glutathione reductase (Red).

The researcher related the occurred increase expressing the increasing activity of those two enzymes to the nature of the type of the training load of varied intensity (water polo match) as the increase in the rate of metabolism to generate power during the training load leads to increase oxidation products as the muscle work of high intensity could result in oxidative stress occurred during the muscle work needing high concentrations of oxygen and in order to have the body tackle such high concentrations of oxygen, a great group of antioxidants stand to get rid of free radicals of oxygen atoms resulted from oxidative stress causing damages to tissues and lowering the level of performance. This explains the increase in the level of concentration and activity of GSH-Per functioning to get rid of free radicals of oxygen atoms. As the level of concentration and activity of this enzyme increase, it indicates to the increase in numbers of free radicals of oxygen atoms. It could be noted in this study that the level of concentration of GSH-Per was increased greatly and it was out of the natural limits after the end of performance directly and after $60 \mathrm{~min}$ from the end of performance indicating that there was a great deal of free radicals of oxygen atoms even after $60 \mathrm{~min}$ from the end of performance. Also the level of concentration and activity of GSH-Red was increased after the end of performance directly and $60 \mathrm{~min}$ 
after the end. It was out of the natural limits indicating that there was an increase in the transformation of glutathione GSSG to glutathione peroxidase to enable the body to get rid of free radicals of oxygen atoms resulted in causing fatigue and damages to cells and consequently, the level of performance gets lower.

These results are in agreement with those achieved by Ferrer et al, (2009), those of Mignini et al, (2008), those of Melikoglu et al, (2008) and those of Powers et al, (1999) that the increase in the level of concentration and activity of GSH-Per and GSH-Red could be related to the increase in free radicals of oxygen atoms resulted from physical exercises of high intensity and that could be considered a cause of damages occurring in cells and consequently, the level of performance got lowered and time for recovery for the athlete was increased $(13,7,8,4)$ and that answers the $1^{\text {st }}$ question in the current research.

Table (4)

Analysis of variance among the three measurements in assessing (MDA)

$(\mathbf{n}=13)$

\begin{tabular}{|c|c|c|c|c|c|}
\hline Source of variance & Sum of squares & DF & Mean of squares & F & Significance \\
\hline Between groups & 4323.12 & 2 & 2161.56 & \multirow{2}{*}{$4180.21 *$} & 0.000 \\
\hline Within groups & 18.61 & 36 & 0.517 & & \\
\hline
\end{tabular}

*Significance $<0.05$

Data in Table (4) reveal that there are statistically significant differences among the three measurements under investigation Malone aldehyde (MDA). Significance of difference was computed through least significance difference (LSD) as indicated in Table (5).

Table (5)

Significance of differences among the three measurements to compute (MDA)

\begin{tabular}{|c|c|c|c|c|}
\hline Measurements & Mean & Pre-measurement & $\begin{array}{c}\text { Directly after } \\
\text { performance }\end{array}$ & $\begin{array}{c}\text { 60 min after } \\
\text { performance }\end{array}$ \\
\hline Pre & 23.84 & $\ldots \ldots \ldots$. & $-24.30 *$ & $-19.61^{*}$ \\
\hline Directly after performance & 48.15 & & $\ldots \ldots \ldots$ & $4.69 *$ \\
\hline 60 min after performance & 43.46 & & & $\ldots \ldots$ \\
\hline
\end{tabular}

Data in Table (5) show the following:

There are statistically significant differences between the pre and directly after the end of performance measurements in favor of the pre-measurement. Also there are statistically significant differences between the pre and $60 \mathrm{~min}$ after the end of performance measurements in favor of $60 \mathrm{~min}$ after the end of performance measurement as well as between directly after the end of performance and $60 \mathrm{~min}$ after the end of it in favor of 60 min after the end of performance measurement in assessing (MDA) variable.

The researcher suggested that the increase in the level of concentration and activity of malone aldehyde considered an indicator of damages affecting cells, lipid peroxidation and oxidative stress, could be related to the varied intensity training load (water polo match) that could increase oxidative stress and lipid peroxidation as the increase in the 
rate of metabolism to generate power during the varied intensity training load could lead to increase peroxidation products due to the increase in lipid oxidation.

Abul-Ela Ahmed Abdel Fattah (1999), Ahmed Qadri Mohammed (2003), Neubauer et al. (2008) and Groussard at al. (2003) confirmed that the increase in the resulted level of concentration of malone aldehyde between the pre-measurement and that of just after performance and $60 \mathrm{~min}$. after performance attributed to increase lipid peroxidation due to catabolism occurred during performance. Thus, some cells got damaged that could be indicated by the increase in the level of concentration of malone aldehyde over its natural rate just after performance and $60 \mathrm{~min}$. after it referring to cell damages. Consequently, the level of performance got lowered. Malone aldehyde did not go back to the natural rate $60 \mathrm{~min}$. after performance referring to incomplete recovery $(6,10,2,1)$ and that answers the $2^{\text {nd }}$ research question.

Table (6)

Analysis of variance among the three measurements in A.As

$(\mathbf{n}=13)$

\begin{tabular}{|c|c|c|c|c|c|}
\hline Sources of variance & $\begin{array}{c}\text { Sum of } \\
\text { squares }\end{array}$ & DF & $\begin{array}{c}\text { Mean of } \\
\text { squares }\end{array}$ & F & Significance \\
\cline { 1 - 4 } Between groups & 16.75 & 2 & 8.37 & \multirow{2}{*}{$96.00 *$} & 0.0000 \\
\hline Within groups & 3.14 & 36 & 0.08 & \\
\hline
\end{tabular}

Sig $<0.05$

Data in Table (6) demonstrate the following: investigation in A.As. Significance of There are statistically significant differences among the three measurements under differences was computed through (LSD) as indicated in Table (7)

Table (7)

Significance of differences among the three measurements in assessing amino acids (A.As)

\begin{tabular}{|c|c|c|c|c|}
\hline Measurements & Mean & Pre-measurement & $\begin{array}{c}\text { Directly after } \\
\text { performance }\end{array}$ & $\begin{array}{c}\text { 60 min after } \\
\text { performance }\end{array}$ \\
\hline Pre & 4.09 & $\ldots \ldots \ldots$ & $-1.60 *$ & $-\mathbf{0 . 6 8 4} *$ \\
\hline Directly after performance & 5.69 & & $\ldots \ldots .$. & $0.915^{*}$ \\
\hline 60 min after performance & 4.77 & & & $\ldots \ldots$ \\
\hline
\end{tabular}

Data in Table (7) reveal the following:

There are statistically significant differences between the pre and directly after the end of performance measurements in favor of the pre-measurement. Also there are significant differences between the pre and $60 \mathrm{~min}$ after the end of performance measurements in favor of the pre-measurement in assessing (A.As) variable.

The researcher resulted that the increase in the level of amino acids considered as an indicator of cell damages and a negative 
indicator of the intensity of muscle work excreted in the varied intensity training load due to the increase in catabolism during the performance and consequently, the proportion of blood amino acids got increased leading to damages in muscle cells.

This result was in harmony with those achieved by Mohammed Ali Al-Qot (2002), Pitkanen et al. (2002) and Nosaka Kazunori (2006) who showed that the resulted increase in the level of amino acids could be attributed to the status of training and competitions of the high level as the performance intensity was at its maximum, hence, the concentration of Cortisol got a higher level and consequently, catabolism was increased during performance. The emerged increase in amino acids in blood serum represented an indicator of cell damages particularly in directly after performance measurement that exceeded the normal limits indicating the intensity of the training load $(11,12,3)$. This answers the $3^{\text {rd }}$ question in the current investigation.

\section{Conclusions}

There were statistically significant differences between the three measurements under investigation in assessing percentage and concentration of glutathione peroxidase (GSH-Per), glutathione reductase (GSHRed), malone aldehyde (MDA) and amino acids (A.As) in favor of the premeasurement.

\section{Recommendations}

1. Depending on glutathione peroxidase and glutathione reductase as indicators of muscle damages or fatigue as well as antioxidants in water polo players.
2. Depending on malone aldehyde as an indicator of muscle damages in water polo players.

3. Depending on the level of amino acids in blood as an indicator of muscle damages as well as a negative indicator of stress hormones in water polo players.

4. Depending on glutathione peroxidase, glutathione reductase, malone aldehyde and amino acids as an indicator of recovery processes after training loads of varied intensities.

5. Making benefit of knowing variations occurring in the activity of glutathione peroxidase, glutathione reductase and malone aldehyde in adjusting and following up training loads.

6. Similar studies should be carried out on other physical activities and different ages.

\section{References}

\section{$\underline{\text { Arabic references }}$}

1. Abul-Ela Ahmed Abdel Fattah: Recovery in the Sports Field, $1^{\text {st }}$ Ed. Arab Thought House, Cairo, 1999.

2. Ahmed Qadri Mohammed Mohammed Mousa: A Dynamic Study of some Physiological and Physical Variables and Their Relation with Oxygen Radicals and Antioxidants during the Training Season. Ph. D. Thesis Unpublished, Faculty of Physical Education for Boys, Helwan University, Cairo, 2003.

3. Mohammed Ali Al-Qot: Physiology of Sport and Swimming Training, $2^{\text {nd }}$ Part, $1^{\text {st }}$ Ed. Arab Publication Center, Cairo, 2002.

\section{Foreign References}

4. Ferrer MD, Tauler P, Sureda A, Tur JA, Pons A. (2009). Antioxidant 
5. regulatory mechanisms in neutrophils and lymphocytes after intense exercise. J. Sports Sci., 27 (1): 49-58.

6. Goodman et al, (1997). Biochemical and altrastructural indices of muscle damage after a twenty-one kilometer run. Aus. J. Sci. Med. Sports, 24 (4): 80 -

95, Australia.

7. Groussard C, Rannou-Bekono F, Machefer G, Chevanne M, Vincent S,

8. Sergent $O$, Cillard $J$ and GratasDelamarche A. (2003). Changes in blood lipid peroxidation markes and antioxidants after a single sprint anaerobic exercise. Eur. J. Appl. Physiol., 89 (1): 14-20.

9. Melikoglu MA, Kaldirimci M, Katkat D, Sen I, Kaplan I and Senel K. (2008).

10. The effect of regular long term training on antioxidant enzymatic activities. J. Sports Med. Phys. Fitness, 48 (3): 388-90.

11. Mignini F, Tomassoni D, Traini $E$ and Streccioni V. (2008). Antioxidant

12. endogenous defense in a human model of physical stress. Clin. Exp. Hypertens, 30 (8): 776-84.

13. Miyazaki H, Oh-ishi S, Ookawara T, Kizaki T, Toshinai K, Ha S, Haga S, Ji

14. LL and Ohna H. (2001). Sternous endurance training in humans reduces oxidative stress following exhausting exercise. Eur. J. Appl. Physiol., 84 (1-2): 1-6.

15. Neubauer O, König D, Kern N, Nics L and Wagner KH. (2008). No indications

16. of persistent oxidative stress in response to an ironman triathlon. Med. Sci. Sports Exerce. 40 (12): 2119-28

17. Nosaka Kazunori (2006). Exercise-induced muscle damage and amino acids.

18. Adv. Exerc. Sports Physiol. Japan.

19. Pitkänen H, Mero A, Oja SS, Komi PV, Pöntinen PJ, Saransaari $P$ and

20. Takala $T$ (2002). Serum amino acid responses to three different exercise sessions in male power athletes. J. Sports Med. Phys. Fitness, 42 (4): 472-80.
21. Powers SK, Ji LL and Leeuwenburgh C. (1999). Exercise training-induced

22. alterations in skeletal antioxidant capacity. Med. Sci. Sports Exec., 31 (7): 1987- 97

\section{Attachment (1)}

Mr.

Parent of player:

After compliments,

The researcher Ala'a Sayed Nabih Khalil is conducting a scientific study entitled "Effect of Intensity Varied Training Load on some Indices of Antioxidants in Water Polo Players". The study needs to withdraw a blood sample of $(4 \mathrm{~cm})$ three times from the player before, directly after the end of the match and 60 min after its end.

Should you agree on withdrawing the sample from the player, please sign here below as an acceptance to include the player as a sample in the current research study for the benefit of science and scientific research.

Thank you very much for your kind cooperation.

Researcher,

Ala'a Sayed Nabih Khalil

Signed by

Parent: 
